\title{
Influence of piston ring profiles and oil temperature distribution on cylinder liner lubrication of a marine two-stroke engine
}

In the paper a comprehensive model of a piston-ring-cylinder (PRC) system has been presented. The local thickness of the oil film can be compared to height of the combined surface roughness of a cylinder liner and piston rings. Equations describing the mixed lubrication problem based on the empirical mathematical model formulated in works of Patir, Cheng and Greenwood, Tripp have been applied. The main parts of the model have been experimentally verified abroad by the author at the marine engine designing centre.

In contrast to the previous papers of the author concerning the PRC system of combustion engines, new calculation results for a marine two-stroke engine have been presented. Firstly the right selection of barrel-shaped sliding surface of piston rings has been analysed. Secondly the influence of oil temperature distribution along the cylinder liner on the lubrication of the PRC system has been assessed. The developed model and software can be useful for optimization of the PRC system design.

Key words: marine engines, piston rings, gasdynamics, hydrodynamic lubrication, mixed friction

\section{Introduction}

Piston rings are important part of internal combustion engines. Commonly a set of piston rings is used to form a dynamic gas seal between the piston and cylinder wall [5, $6,13]$. The sliding motion of the piston forms a thin oil film between the ring land and cylinder wall, which lubricates the sliding components $[2,4,11]$. The hydrodynamic force generated by this thin oil film is opposed by a combination of the gas pressure acting on the back side of each ring and the ring stiffness. Due to the dynamic nature of these forces, each individual ring is periodically compressed and extended as the piston runs through its cycle. The problem of studying this interaction is further complicated by the high temperatures involved, as these result in low oil viscosity and subsequently very low oil film thickness. The oil film is typically thick enough to expect the existence of mixed lubrication, so this phenomenon should also be taken into account $[2,7,8,12,13]$. The use of modern oil of low viscosity, working at a high temperature causes the existence of a very thin oil film thickness comparable to the value of the liner surface roughness. In such conditions, the possibility of direct contact between the ring and cylinder liner surface exists. Therefore the numerical simulation of these processes, which take place in a typical piston ring pack operation, is important from practical point of view.

The purpose of this paper is to present numerical calculations concerning an influence of selected barrel-shaped sliding surfaces of piston rings and oil temperature distribution on cylinder liner lubrication of the PRC system.

\section{Modelling of piston ring pack operation}

\subsection{Developed sub-models}

A combined model of piston rings operation has been developed. It consists of two main models: a) model of gas flow through the labyrinth seal piston-rings-cylinder (PRC), b) model of oil flow in the lubrication gap between the ring and cylinder liner. The two aforementioned models are coupled. In addition, sub-models of the following mechanical phenomena have been used: a contact of rough surfaces, an axial movement of rings within piston grooves and an elastic torsional deformation of piston rings (Fig. 1). All the sub-models are described in detail in publications [15-19] of the author. In this paper only the sub-model of mixed lubrication $[3,9,18]$ is shortly presented.

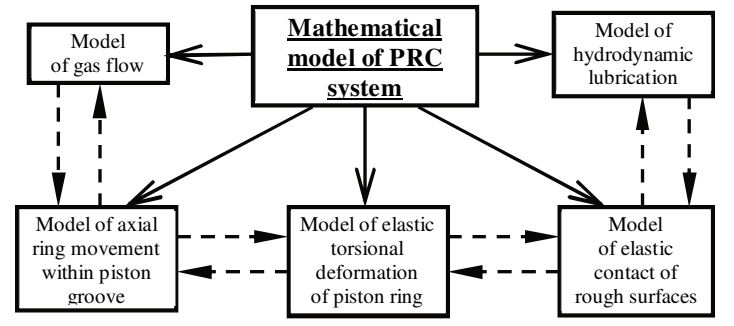

Fig. 1. Developed comprehensive model of the system: piston-ringcylinder (PRC)

\subsection{Model of mixed lubrication}

Two main cases of oil flow in the system piston ring cylinder liner are presented in Fig. 2.
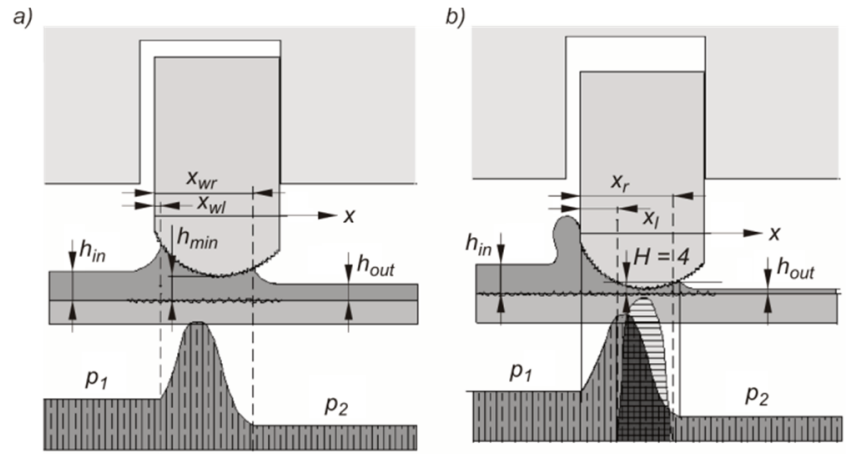

Fig. 2. Scheme of gap between the ring face and cylinder liner in the case of: a) fluid and b) mixed friction

A one dimensional form of the modified Reynolds equation developed by Patir and Cheng [9] has been used to calculate hydrodynamic forces in the case of rough gap surfaces. This equation is applicable to any general roughness structure and takes the following form:

$$
\frac{\partial}{\partial \mathrm{x}}\left(\phi_{\mathrm{x}} \frac{\mathrm{h}^{3}}{12 \mu} \frac{\mathrm{d} \overline{\mathrm{p}}}{\mathrm{dx}}\right)=\frac{\mathrm{U}}{2} \frac{\mathrm{d} \overline{\mathrm{h}}_{\mathrm{T}}}{\mathrm{dx}}+\frac{\mathrm{U}}{2} \sigma \frac{\mathrm{d} \phi_{\mathrm{S}}}{\mathrm{dx}}+\frac{\mathrm{d} \overline{\mathrm{h}}_{\mathrm{T}}}{\mathrm{dt}}
$$


where: $\mathrm{t}$ - time; $\mathrm{x}$ - coordinate along cylinder liner; $\mathrm{h}$ nominal oil film thickness; $\mathrm{h}_{\mathrm{T}}$ - average gap (ringcylinder); $\mathrm{p}$ - hydrodynamic pressure; $\mathrm{U}$ - axial ring velocity; $\mu$-dynamic oil viscosity; $\mathrm{v}=\partial \mathrm{h}_{\mathrm{T}} / \partial \mathrm{t}$ - radial ring velocity, $\sigma$ - composite root mean square roughness of sliding surfaces.

The significance and mathematical description of empirical coefficients $\phi_{\mathrm{x}}, \phi_{\mathrm{S}}$ and boundary conditions of equation (1) are presented in [9].

The effects of interacting asperities of piston ring and cylinder liner surfaces were modelled using the mathematical model developed by Greenwood and Tripp [3]. In this case the asperity contact force per unit circumference is given by

$$
\mathrm{F}_{\mathrm{C}}=16 \sqrt{\frac{2}{15}} \pi(\eta \beta \sigma)^{2} \mathrm{E}^{\prime} \sqrt{\left(\frac{\sigma}{\beta}\right)} \int_{\mathrm{x}_{1}}^{\mathrm{x}_{\mathrm{r}}} \mathrm{F}_{5 / 2}\left(\frac{\mathrm{h}}{\sigma}\right) \mathrm{dx}
$$

where the integration limits $\mathrm{x}_{1}$ and $\mathrm{x}_{\mathrm{r}}$ define a continuous interval, $\mathrm{x}_{1} \leq \mathrm{x} \leq \mathrm{x}_{\mathrm{r}}$ in which $\mathrm{h} / \sigma \leq 4$ and: $\mathrm{E}$ ' - composite elastic modulus (for cylinder liner and piston ring); $\eta-$ asperity density; $\beta$ - asperity radius of curvature; $\sigma-$ combined root mean square roughness of both sliding surfaces.

The form of function $\mathrm{F}_{5 / 2}$ can be found in article [3]. The model is also described in detail in publication [18] of the author of this article.

\subsection{Viscosity as a function of oil temperature}

The viscosity of the oil used for lubrication is a key factor influencing oil film thickness. Marine engines have a relatively high temperature of oil film and due to that a relatively low oil viscosity. This explains the very thin oil film left by the periodically moving ring pack. In the analysis presented, it was assumed that the oil film temperature is equal to the liner temperature.

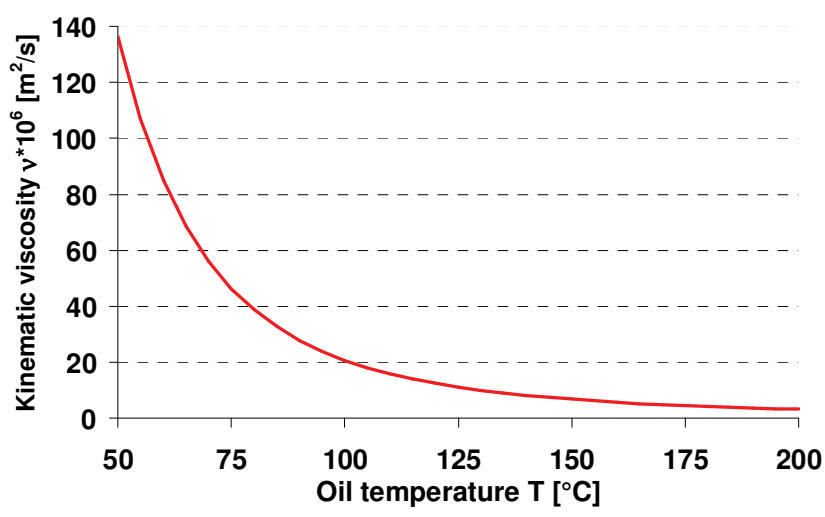

Fig. 3. Oil viscosity versus temperature

The temperature-dependent oil viscosity $v(T)$ was evaluated by the use of following equation (Fig. 3):

$$
\log _{10}\left[\log _{10}(v+0.8)\right]=A_{v}-B_{v} \log _{10} T
$$

where parameters: $\mathrm{A}_{v}=8.56$ and $\mathrm{B}_{v}=3.28$.

The assumed oil density $\rho=940 \mathrm{~kg} / \mathrm{m}^{3}$ and the lubricating oil feed rate at full engine load $g_{o i l}=1 \mathrm{~g} / \mathrm{kWh}$ [18].

\subsection{The geometry of the ring lip}

The sliding surface of a piston ring shouldn't be treated as an internal cylindrical or conical surface. It is rather a barrel-shaped surface (Fig. 4).

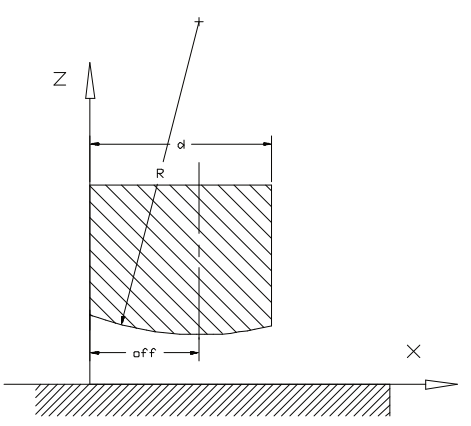

Fig. 4. Piston ring geometry: $\mathrm{d}$ - ring axial height, $\mathrm{R}$ - radius of the ring surface, $\mathrm{O}_{\mathrm{ff}}-$ offset of the ring sliding surface

The profile of the sealing ring is described by

$$
h(x)=h_{\min }+\frac{\left(x-O_{f f}\right)^{2}}{2 R} \text { for } 0 \leq x \leq d
$$

where: $\mathrm{h}_{\min }-$ minimum gap height (Fig. 2); $\mathrm{d}$ - ring axial height, $\mathrm{R}$ - radius of the ring surface, $\mathrm{O}_{\mathrm{ff}}-$ offset of the ring sliding surface.

One problem is the definition of the profile geometry of the scraper ring. Initially manufactured as a linear oblique surface with sharp edges, after approximately 600 hours of running it is worn out and its shape can be modelled as a parabolic with very large radius.

\section{Experimental verification of developed model}

A verification of the simulation model has been done by the author for a two- and four-stroke marine engine $[15,16$, 18]. The experimental verification of the model of gas flow through the labyrinth seal of piston rings was carried out using measurements of unsteady gas pressure in the cylinder, between the piston rings and under piston performed by piezoelectric sensors mounted in the piston. A satisfactory qualitative and quantitative compatibility of the analyzed pressure variations has been achieved. The maximal relative differences between measured and calculated pressure values have not exceeded $15 \%[15,18]$. On the other hand, the experimental verification of the hydrodynamic model of piston rings involved measurement results of scraped oil volumes by a gland-box of a two-stroke marine engine. Unfortunately, similar measurements for piston ring packs of tested engines have not been carried out. Examination of scraped oil volumes by the ring pack (of the gland-box of marine internal combustion engine) proves a satisfactory quantitative agreement between numerical and experimental results. The maximal relative differences between measured and calculated values have not exceeded $10 \%$ $[15,18]$.

\section{Calculation results}

\subsection{Main data of chosen engine}

The computer program incorporating the presented model has been used for simulation of two-stroke Diesel engine (Table 1) operating at full load. 
Table 1. Main data of the marine engine under consideration [14]

\begin{tabular}{|l|c|}
\hline Cylinder bore & $960 \mathrm{~mm}$ \\
\hline Piston stroke & $2500 \mathrm{~mm}$ \\
\hline Engine rotational speed & $102 \mathrm{rpm}$ \\
\hline
\end{tabular}

The type of ring set considered is common in marine engines. The piston ring pack consists of four rings. The package includes conventional straight ring end gaps.

The surface geometry of the piston ring package, with vertical dimensions magnified by factor of 1000 relative to the horizontal ones, is depicted in Fig. 5.

All the rings have the same asymmetrical barrel shape (Fig. 5, Table 2).

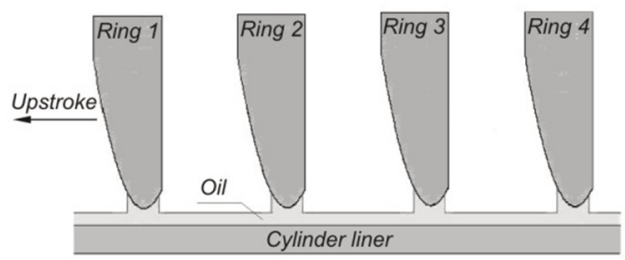

Fig. 5. Ring pack geometry under consideration

In order to ensure very low wear of profiled surfaces, the piston rings are coated (for example the top ring has chromium ceramic coating) $[1,10]$. As a consequence, even hydrodynamic conditions during a long period of piston rings operation can be ensured.

Table 2. Basic geometric parameters of piston rings: 1, 2, 3, 4

\begin{tabular}{|l|l|}
\hline Axial height of piston ring & $\mathrm{H}=20 \mathrm{~mm}$ \\
\hline Radius of parabolic sliding surface & $\mathrm{R}=950 \mathrm{~mm}$ \\
\hline Offset of parabolic sliding surface & $\mathrm{O}_{\mathrm{ff}}=15 \mathrm{~mm}$ \\
\hline Distance between piston rings & $\mathrm{L}_{\mathrm{p}}=34 \mathrm{~mm}$ \\
\hline
\end{tabular}

The main parameters of the rough structure of the cylinder liner and sliding surfaces of piston rings are presented in Table 3.

Table 3. Surface roughness parameters

\begin{tabular}{|l|l|l|}
\hline \multicolumn{1}{|c|}{ Surface parameters } & \multicolumn{1}{|c|}{ Cylinder liner } & \multicolumn{1}{c|}{ Piston rings } \\
\hline RMS roughness & $\sigma_{1}=0.22 \mu \mathrm{m}$ & $\sigma_{2}=0.044 \mu \mathrm{m}$ \\
\hline Elastic modulus & $\mathrm{E}_{1}=1.13 \cdot 10^{11} \mathrm{~N} / \mathrm{m}^{2}$ & $\mathrm{E}_{2}=1.5 \cdot 10^{11} \mathrm{~N} / \mathrm{m}^{2}$ \\
\hline Poisson's ratio & $v_{\mathrm{P} 1}=0.26$ & $v_{\mathrm{P} 2}=0.25$ \\
\hline Combined parameters & \multicolumn{1}{|c|}{ Cylinder liner and piston rings } \\
\hline RMS roughness & \multicolumn{2}{|c|}{$\sigma=0.224 \cdot 10^{-6} \mathrm{~m}$} \\
\hline Asperity density & \multicolumn{2}{|c|}{$\eta=1.114 \cdot 10^{12} \mathrm{~m}^{-2}$} \\
\hline $\begin{array}{l}\text { Asperity radius } \\
\text { of curvature }\end{array}$ & \multicolumn{2}{|c|}{$\beta=0.2 \cdot 10^{-6} \mathrm{~m}$} \\
\hline
\end{tabular}

The roughness parameters of sliding surfaces of piston rings were determined using mechanical contact measurement method, namely a standard surface roughness tester. The roughness of cylinder liner was non-destructively evaluated and in detail analyzed by the application of new optical measurement methods. It was possible at any stage of the life-time of cylinder liner by the use of rubber compound replicas of the liner surface [10].

\subsection{Influence of piston ring profiles}

\subsubsection{First (top) piston ring}

At first two profiles of the $1^{\text {st }}$ (top) piston ring, i.e. with offset of the ring sliding surface $\mathrm{O}_{\mathrm{ff}}=15 \mathrm{~mm}$ and offset
$\mathrm{O}_{\mathrm{ff}}=5 \mathrm{~mm}$ (Figs 6,7) have been analysed in the lubrication aspect of the cylinder liner. a)

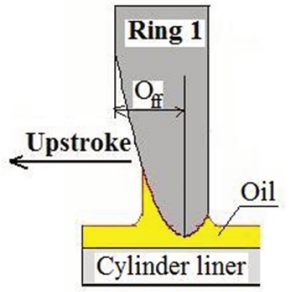

b)

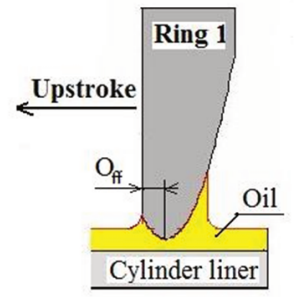

Fig. 6. Analysed profiles of the $1^{\text {st }}$ (top) piston ring: a) offset of the ring sliding surface $\mathrm{O}_{\mathrm{ff}}=15 \mathrm{~mm}, \mathrm{~b}$ ) offset $\mathrm{O}_{\mathrm{ff}}=5 \mathrm{~mm}$

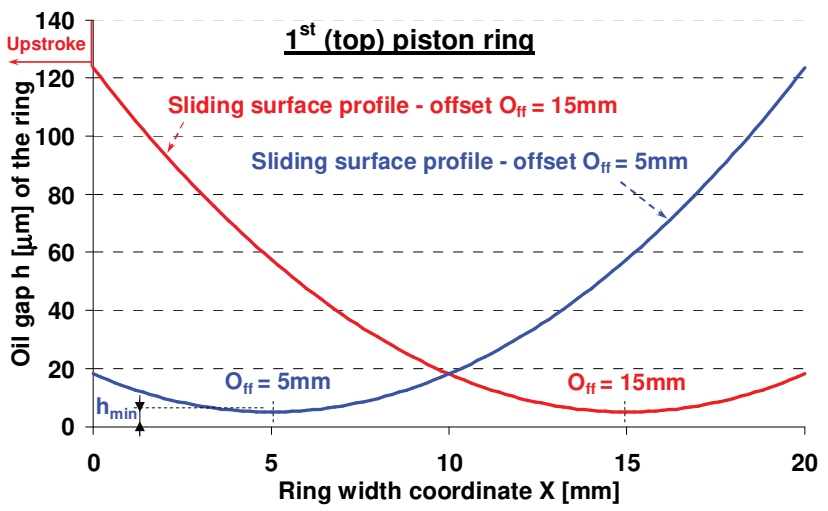

Fig. 7. Comparison of two chosen profiles of the $1^{\text {st }}$ (top) piston ring: chosen offsets of the ring sliding surface $\mathrm{O}_{\mathrm{ff}}=15 \mathrm{~mm}$ and $\mathrm{O}_{\mathrm{ff}}=5 \mathrm{~mm}$; $\mathrm{h}_{\min }-$ minimum oil film thickness

The main parameters of the top piston ring and its sliding surface are presented in Table 4.

Table 4. Basic geometric parameters of the 1st (top) piston ring

\begin{tabular}{|l|c|c|}
\hline \multicolumn{1}{|c|}{ Parameter } & Case 1 & Case 2 \\
\hline Axial height of piston ring & $\mathrm{H}=20 \mathrm{~mm}$ & $\mathrm{H}=20 \mathrm{~mm}$ \\
\hline Radius of parabolic sliding surface & $\mathrm{R}=950 \mathrm{~mm}$ & $\mathrm{R}=950 \mathrm{~mm}$ \\
\hline Offset of parabolic sliding surface & $\mathrm{O}_{\mathrm{ff}}=15 \mathrm{~mm}$ & $\mathrm{O}_{\mathrm{ff}}=5 \mathrm{~mm}$ \\
\hline
\end{tabular}

The motion of the ring pack scraping and distributing oil on the cylinder liner leaves the oil film profile shown in Fig. 8. This profile is formed after a few cycles of operation. An uneven oil film distribution along the cylinder liner can be clearly seen. Low film thickness near TDC and in the other part of cylinder liner at the location of scavenging air ports should be noticed. The minimum oil film thickness at TDC is about $0.2-0.3 \mu \mathrm{m}$ and is comparable with root mean square (RMS) roughness of the cylinder liner that equals $0.22 \mu \mathrm{m}$ [18]. The very low local film thickness values near TDC can be explained by occurrence of high gas pressure and high temperature in this area during the compression and working phases of engine operation. Due to high gas forces piston rings are strongly pressed against the cylinder surface. On the other hand, high temperature reduces the oil viscosity.

There are two places of oil supply for the cylinder liner of long-stroke IC engine located below TDC. Two peaks of oil film thickness at these places can be clearly seen in Fig. 8. 
In a marine two-stroke engine the location of scavenging air ports is also important for cylinder lubrication. Their presence simply reduces the area of the mating surface between piston rings and cylinder liner. In this area a simplified approach was applied. The oil film thickness was assumed to be reduced at this location reflecting the reduced sliding surface.

Due to low gas pressure and oil temperature the greatest oil film thickness can be seen between scavenging air ports and the bottom dead centre (BDC).

Near the piston top dead centre (TDC) and between two places of oil supply a slightly bigger oil film thickness is noticed in the case of the offset of the ring sliding surface $\mathrm{O}_{\mathrm{ff}}=15 \mathrm{~mm}$ than in the case of the offset $\mathrm{O}_{\mathrm{ff}}=5 \mathrm{~mm}$. For this reason the lubrication conditions near TDC are better in the first case. In addition less amount of oil scraped to the combustion chamber can be expected.

But from the middle of the cylinder wall to the location of scavenging air ports an opposite situation is observed, i.e. lower oil film thickness is noticed in the case of the offset of the ring sliding surface $\mathrm{O}_{\mathrm{ff}}=15 \mathrm{~mm}$ than in the case of the offset $\mathrm{O}_{\mathrm{ff}}=5 \mathrm{~mm}$ (Fig. 8).

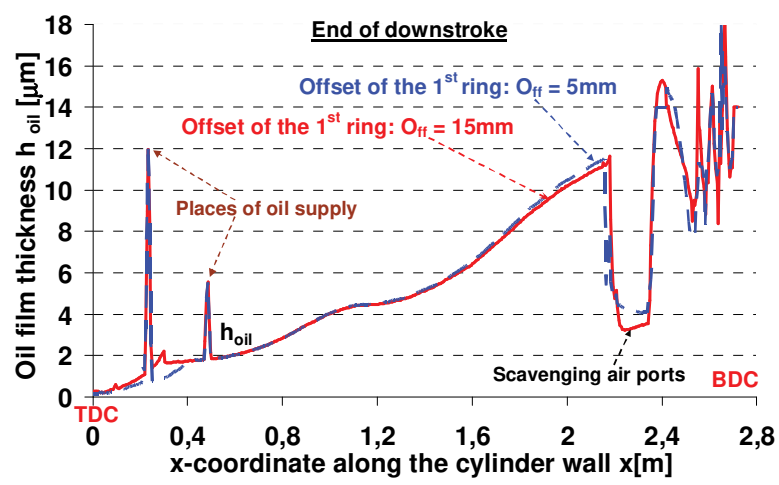

Fig. 8. Comparison of the oil film thickness $\mathrm{h}_{\mathrm{oil}}[\mu \mathrm{m}]$ left by the piston ring pack along cylinder wall in case of the offset $\mathrm{O}_{\mathrm{ff}}=5 \mathrm{~mm}$ and $\mathrm{O}_{\mathrm{ff}}=15 \mathrm{~mm}$ of the $1^{\text {st }}$ (top) ring

A confirmation of the described results can be noticed in Fig. 9, where the minimum oil film thickness (see Fig. 2) in the gap of the top piston ring versus crank angle is shown. A similar comparison of lubrication conditions concerning the offset of the $1^{\text {st }}$ piston ring $\left(\mathrm{O}_{\mathrm{ff}}=15 \mathrm{~mm}\right.$ and $\mathrm{O}_{\mathrm{ff}}=5 \mathrm{~mm}$ ) can be done.

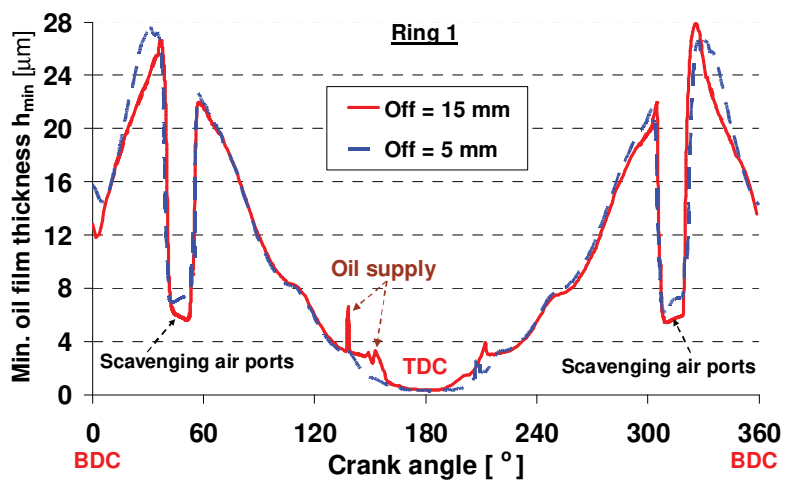

Fig. 9. Comparison of the minimum oil film thickness $h_{\min }[\mu \mathrm{m}]$ of the $1^{\text {st }}$ (top) piston ring in case of its offset $\mathrm{O}_{\mathrm{ff}}=5 \mathrm{~mm}$ and $\mathrm{O}_{\mathrm{ff}}=15 \mathrm{~mm}$
But at first it should be explained that hydrodynamic forces generated in the gap between liner and ring lip are proportional to the ring axial velocity. During a cycle, the axial velocity tends to zero near the turning points (TDC and BDC). In these areas, the oil film thickness is strongly reduced, because the only force acting against the gas and ring stiffness forces is the hydrodynamic force generated by the squeeze velocity. This means that the squeeze velocity should be relatively high.

Near the piston top dead centre (TDC) and between crank angles of oil supply (Fig. 9) a slightly bigger oil film thickness is noticed in the case of the offset of the $1^{\text {st }}$ piston ring $\mathrm{O}_{\mathrm{ff}}=15 \mathrm{~mm}$ than in the case of the offset $\mathrm{O}_{\mathrm{ff}}=5 \mathrm{~mm}$. In addition less amount of oil scraped to the combustion chamber can be expected.

\subsubsection{Asymmetric and symmetric profiles of piston rings: 2,3} and 4

Two piston ring pack configurations, i.e. asymmetric profiles of all rings and symmetric profiles of rings 2, 3 and 4, have been analysed (Fig. 10 and Tab. 5).
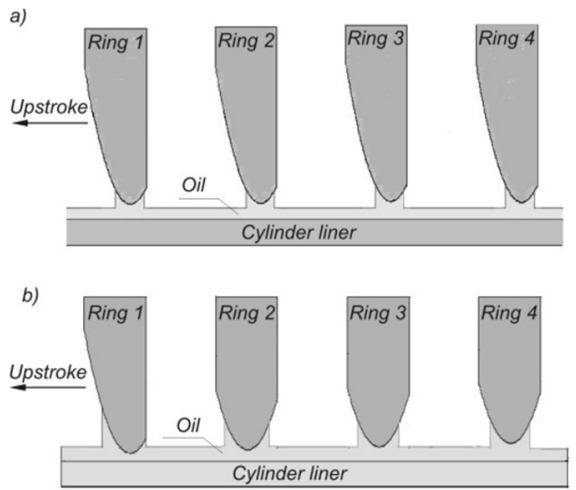

Fig. 10. Piston ring pack geometry under consideration: a) asymmetrical barrel shape of all rings, b) symmetrical barrel shape of rings 2, 3 and 4

The details concerning the considered offset of piston rings are given in Table 5 .

Table 5. Chosen geometric parameter of piston rings 2, 3 and 4

\begin{tabular}{|c|c|c|}
\hline Parameter & $\begin{array}{c}\text { Asymmetrical } \\
\text { barrel shape }\end{array}$ & $\begin{array}{c}\text { Symmetrical } \\
\text { barrel shape }\end{array}$ \\
\hline Offset of sliding surface & $\mathrm{O}_{\mathrm{ff}}=15 \mathrm{~mm}$ & $\mathrm{O}_{\mathrm{ff}}=10 \mathrm{~mm}$ \\
\hline
\end{tabular}

The most important calculation results under consideration are depicted in Fig. 11.

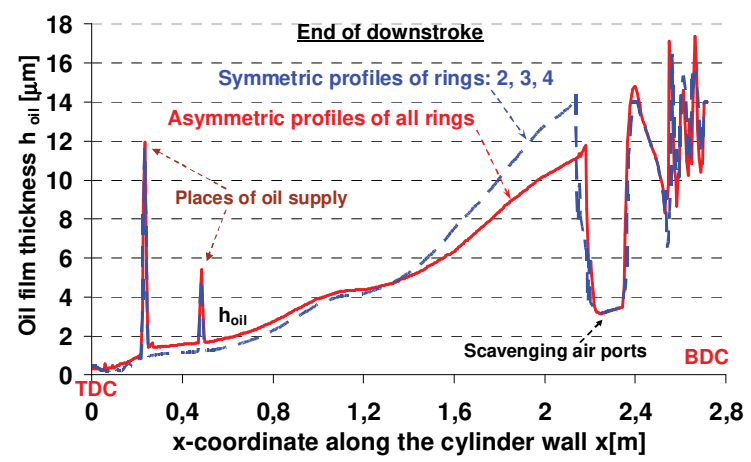

Fig. 11. Comparison of the oil film thickness $h_{\text {oil }}[\mu \mathrm{m}]$ left by the piston ring pack along cylinder wall in case of asymmetric profiles of all rings and symmetric profiles of rings $2,3,4$ 
Near the piston top dead centre (TDC) and between two places of oil supply a slightly lower oil film thickness is noticed in the case of symmetric profiles of rings $2,3,4$ than in the case of asymmetric profiles of all rings. For this reason the lubrication conditions near TDC are slightly worse in the first case.

But from the middle of the cylinder wall to the location of scavenging air ports an opposite situation is observed, i.e. much bigger oil film thickness is noticed in the case of symmetric profiles of rings $2,3,4$ than in the case of asymmetric profiles of all rings (Fig. 11).

A confirmation of the described results can be noticed in Fig. 12, where the minimum oil film thickness (see Fig. 2) in the gap of the top piston ring versus crank angle is shown. A similar comparison of lubrication conditions concerning asymmetric profiles of all rings and symmetric profiles of rings 2, 3 and 4 can be done.

Near the piston top dead centre (TDC) and at crank angles of oil supply a slightly lower oil film thickness is noticed in the case of symmetric profiles of rings 2, 3, 4 than in the case of asymmetric profiles of all rings. But at other crank angles, especially near scavenging air ports, much bigger oil film thickness is noticed in the first than in the second case (Fig. 12).

This is the reason that in new engine types the symmetric barrel shape of piston ring (2, 3 and 4) is used [10].

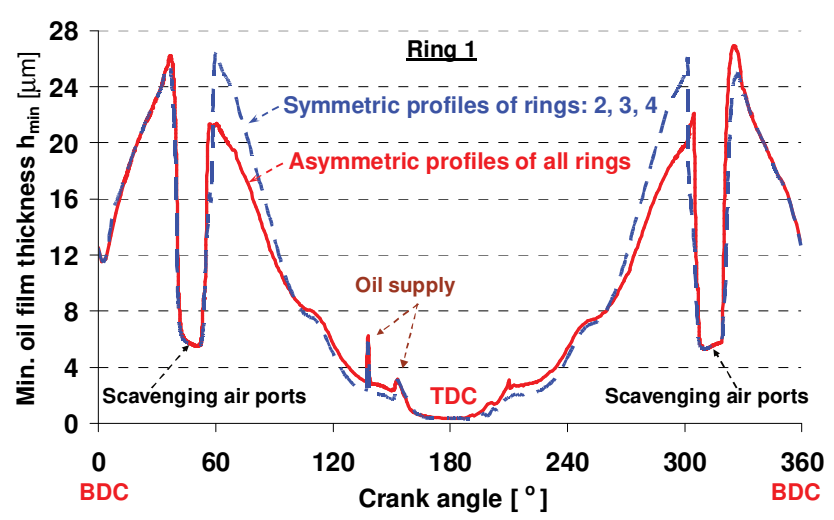

Fig. 12. Comparison of the minimum oil film thickness $h_{\min }[\mu \mathrm{m}]$ of the $1^{\text {st }}$ (top) piston ring in case of asymmetric profiles of all rings and symmetric profiles of rings $2,3,4$

\subsection{Influence of oil temperature distribution along the cylinder wall}

Finally the influence of oil temperature at the piston TDC on cylinder liner lubrication has been analysed. The appropriate calculations in the case of standard and $30^{\circ} \mathrm{C}$ lower oil temperature at TDC have been made.

The second case can be technically achieved when more effective cooling system of cylinder liner near TDC is made.

The detailed data concerning thermal state of cylinder liner was proprietary information of the engine development company (see Acknowledgments). Therefore only dimensionless relations could be presented in Fig. 13.

It has been assumed that temperatures of the oil film and cylinder liner are the same.

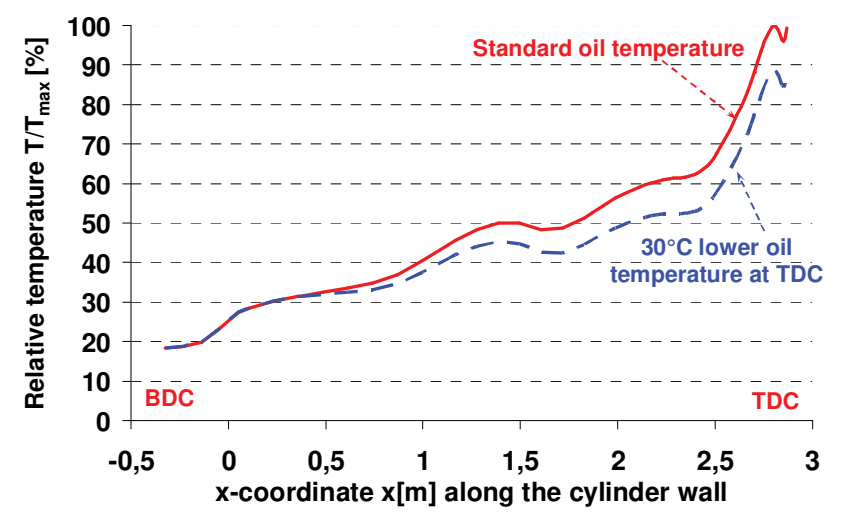

Fig. 13. Relative variations of temperature T/Tmax [\%] of cylinder liner at full engine load

From places of oil supply to the location of scavenging air ports considerably bigger oil film thickness is noticed in the case of lower oil temperature than in the case of standard oil temperature. In addition a slightly bigger oil film thickness can be seen near the piston TDC (Fig. 14).

For this reason the lubrication conditions in this area of cylinder liner are much better in the first case. Therefore the lowering of temperature of cylinder liner at the piston TDC is important from practical point of view.

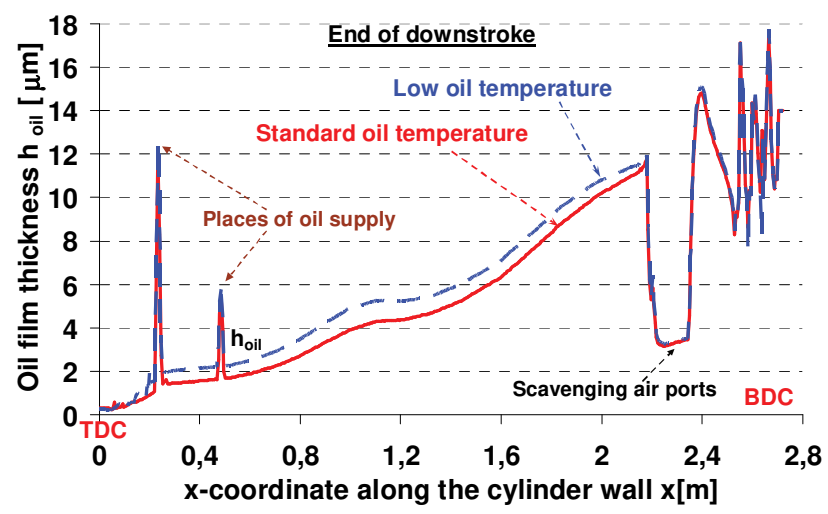

Fig. 14. Comparison of the oil film thickness $h_{\text {oil }}[\mu \mathrm{m}]$ left by the piston ring pack along cylinder wall in case of standard oil temperature and lower oil temperature distribution on cylinder liner

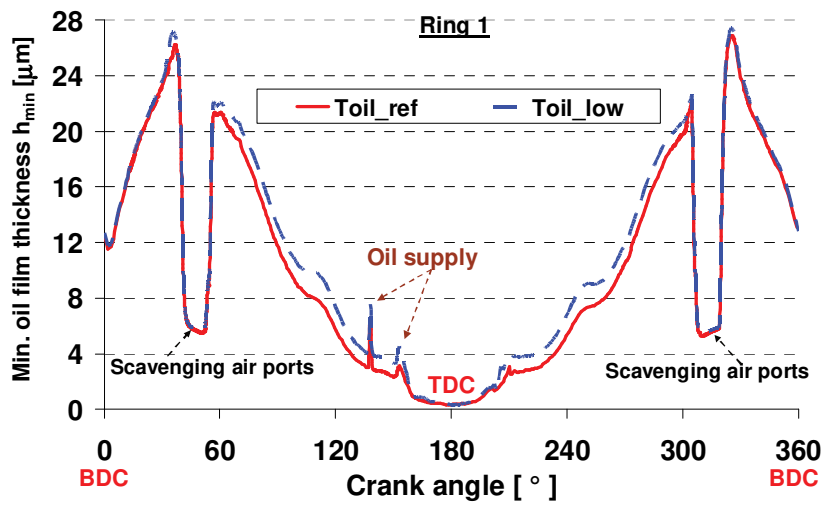

Fig. 15. Comparison of the minimum oil film thickness $h_{\min }[\mu \mathrm{m}]$ of the $1^{\text {st }}$ (top) piston ring in case of standard oil temperature and lower oil temperature distribution on cylinder liner 
A confirmation of the described results can be seen in Fig. 15, where the minimum oil film thickness (see Fig. 2) in the gap of the top piston ring versus crank angle is shown. A similar comparison of lubrication conditions concerning standard oil temperature and lower oil temperature distribution on cylinder liner can be done.

Significantly bigger oil film thickness is noticed at crank angles from the location of scavenging air ports to oil supply places in the second than in the first case. In addition a slightly bigger oil film thickness can be seen near the piston TDC (Fig. 15). Therefore more effective cooling system of cylinder liner near TDC should be recommended.

\section{Conclusions}

The major conclusions that may be drawn from the results are as follows:

1. The developed mathematical model and simulation program give a lot of practical information that would be more complicated and expensive to obtain using experimental methods.

2. At first two profiles of the $1^{\text {st }}$ (top) piston ring, i.e. with offset of the ring sliding surface $\mathrm{O}_{\mathrm{ff}}=15 \mathrm{~mm}$ and offset $\mathrm{O}_{\mathrm{ff}}=5 \mathrm{~mm}$ (Figs 6,7 ) have been compared in the lubrication aspect of the cylinder liner. In the first case the following main phenomena can be noticed (Figs 8, 9):

- slightly bigger oil film thickness near the piston top dead centre (TDC) and between two places of oil supply,

- lower oil film thickness from the middle of the cylinder liner to the location of scavenging air ports,

- less oil amount scraped to the combustion chamber.
3. Then two piston ring pack configurations, i.e. asymmetric profiles of all rings and symmetric profiles of rings 2, 3 and 4 (Fig. 10), have been analysed. In the second case the following phenomena can be noticed (Figs 11, 12):

- much bigger oil film thickness from the middle of the cylinder liner to the location of scavenging air ports,

- slightly lower oil film thickness near the piston top dead centre (TDC) and between two places of oil supply.

4. Finally the influence of oil temperature at the piston TDC (Fig. 13) on cylinder liner lubrication has been analysed. In the case of lower oil temperature than in standard case the following phenomena can be noticed (Figs 14, 15):

- significantly bigger oil film thickness from the places of oil supply to the location of scavenging air ports,

- slightly bigger oil film thickness near TDC,

- therefore more effective cooling system of cylinder liner near TDC should be recommended.

5. The main aim of simulation of piston rings operation is to predict lubrication conditions, define areas of the possible cylinder liner wear and finally determine the gas leakage through the sealing ring set. Further investigation of these phenomena should be recommended.

\section{Acknowledgements}

The author expresses his gratitude to Wärtsilä's R\&D engine centre (nowadays: Winterthur Gas \& Diesel Ltd.) in Winterthur (Switzerland) for having the opportunity to work on projects concerning mathematical modelling and numerical simulation of tribological systems of piston rings during several research periods at this company.

\section{Nomenclature}

PRC piston-ring-cylinder

TDC top dead centre
BDC bottom dead centre

RMS root mean square

\section{Bibliography}

[1] DEMMERLE, R., BARROW, S., TERRETTAZ, F., JAQUET, D. New insights into the piston running behaviour of "Sulzer" large bore diesel engines. CIMAC Congress. Hamburg 2001.

[2] DOWSON, D. Piston assemblies; background and lubrication analysis, engine tribology. Taylor C.M. (ed.). Elsevier Science. 1993, 213-240.

[3] GREENWOOD, J., TRIPP, J.H. The contact of two nominally flat rough surfaces. Proc Inst. Mech. Eng. 1971, 185, 625-633.

[4] ISKRA, A. Parametry filmu olejowego w węzłach mechanizmu tłokowo-korbowego silnika spalinowego. Wydawnictwo Politechniki Poznańskiej. Poznań 2001.

[5] KOSZAŁKA, G. Application of the piston-rings-cylinder kit model in the evaluation of operational changes in blowby flow rate. Eksploatacja i Niezawodność - Maintenance and Reliability. 2010, 4, 72-81.

[6] KOSZAŁKA, G., GUZIK, M. Mathematical model of piston ring sealing in combustion engine. Polish Maritime Research. 2014, 4(84), 21, 66-78.

[7] LIVANOS, G.A., KYRTATOS, N.P. Friction model of a marine diesel engine piston assembly. Tribology International. 2007, 40, 1441-1453.
[8] OFFNER, G. Friction power loss simulation of internal combustion engines considering mixed lubricated radial slider, axial slider and piston to liner contacts. Tribology Transactions. 2013, 56(3), 503-515.

[9] PATIR, N., CHENG, H.S. Application of average flow model to lubrication between rough sliding surfaces. Transactions of ASME. 1979, 101.

[10] RÄSS, K., AMOSER, M. Progressive development of twostroke engine tribology. CIMAC Congress. 2007, 83.

[11] SERDECKI, W. Badania współpracy elementów układu tłokowo-cylindrowego silnika spalinowego. Wydawnictwo Politechniki Poznańskiej, Poznań 2002.

[12] TAMMINEN, J., SANDSTRÖM, C.-E., ANDERSSON, P. Influence of load on the tribological conditions in piston ring and cylinder liner contacts in a medium-speed diesel engine. Tribology International. 2006, 39, 1643-1652.

[13] TIAN, T. Dynamic behaviors of piston rings and their practical impact - part II: oil transport, friction, and wear of ring/liner interface and the effects of piston and ring dynamics. Proc. I. Mech. E, Part J: Journal of Engineering Tribology. 2002, 216, 229-247.

[14] Wärtsilä Technology Review, information materials concerning IC engines designed at Wärtsilä company. 
[15] WOLFF, A. Experimental verification of the model of piston ring pack operation of an internal combustion engine. The Archive of Mechanical Engineering. 2009, LVI, 1, 7390.

[16] WOLFF, A. Numerical analysis of piston ring pack operation of a marine two-stroke engine. Combustion Engines. 2011, 146(3).
[17] WOLFF, A. Influence of engine load on piston ring pack operation of a marine two-stroke engine. Journal of KONES Powertrain and Transport. 2012, 19(2), 557-569.

[18] WOLFF, A. Simulation based study of the system pistonring-cylinder of a marine two-stroke engine. Tribology Transactions. 2014, 57(4), 653-667.

[19] WOLFF, A. Influence of piston ring pack configuration on blowby and friction losses in a marine two-stroke engine. Combustion Engines. 2017, 170(3), 164-170.

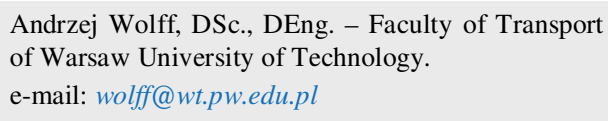

